07

\title{
Угловая селективность амплитудно-фазовых голограммных решеток в полимерном материале с фенантренхиноном
}

\author{
(C) В.Н. Борисов, А.В. Вениаминов
}

Университет ИТМО, 197101 Санкт-Петербург, Россия

e-mail: borisov.itmo@gmail.com

Поступила в редакцию 20.02.2018 г.

\begin{abstract}
Значения амплитуд модуляции показателя преломления и коэффициента поглощения в объемных голограммных решетках, записанных в полимерном материале с фенантренхиноном $(\Phi \mathrm{X})$, определены по результатам аппроксимации контуров угловой селективности, измеренных на длинах волн 450, 473, 532 и $633 \mathrm{~nm}$ до и после проявления (усиления) голограмм, происходящего за счет диффузии молекул ФХ в стеклообразном полимере. Сразу после записи, до диффузионного проявления, голограммы являются смешанными амплитудно-фазовыми в спектральной области поглощения ФХ и фазовыми для не поглощаемого им красного света $(633 \mathrm{~nm})$, а в ходе проявления становятся фазовыми независимо от длины волны. Форма контура селективности непроявленной голограммы указывает на противофазность модуляции коэффициента поглощения и показателя преломления, иллюстрируя концепцию дополнительных решеток, на которой базируется принцип формирования голограмм в рассматриваемом материале.
\end{abstract}

DOI: $10.21883 /$ OS.2018.06.46092.47-18

\section{Введение}

Хотя развитие цифровых технологий вытесняет или уже вытеснило светочувствительные материалы из многих традиционных применений, в том числе и голографических, объемная голография по-прежнему базируется на средах, меняющих свои оптические свойства под действием света и вследствие этого изменяющих падающий на них волновой фронт. Активно идут разработка, исследование и совершенствование светочувствительных материалов на основе кристаллов, стекол, полимеров.

Селективность, угловая и спектральная, является отличительной чертой объемных голограмм, обеспечивая возможность создания на их основе оптических элементов, элементов памяти, трехмерных изображений. Конкретная форма зависимости дифракционной эффективности от угла падения светового пучка на голограмму (контура селективности) определяется оптическими и геометрическими (толщина) характеристиками голограммы, и знание этой зависимости может позволить определить численные характеристики голограммы и содержащего ее материала. Математические модели, описывающие контуры угловой селективности голограммных решеток различной природы, базируются на теории связанных волн Когельника [1]. В работе [2] такая модель была применена к объемным пропускающим и отражательным голограммам (решеткам) без фазового сдвига. Позднее многие ученые занимались совершенствованием данной модели $[3,4]$. Используемый в данной работе вариант математического аппарата с учетом расхождения решеток по фазе был предложен в 2008 г. [5,6], где уравнения, описывающие \pm 1 -е и нулевой порядки дифракции, выглядят следующим образом:

$$
\begin{array}{rl}
\eta_{ \pm 1}=2 & A(\theta) \frac{\kappa_{1}^{2}+\kappa_{2}^{2} \pm 2 \kappa_{1} \kappa_{2} \sin \varphi}{z} \\
& \times[\cosh (\sqrt{z} D \cos \psi)-\cos (\sqrt{z} D \sin \psi)], \\
\eta_{0}= & \frac{A(\theta)}{2 z}\left[\left(z+\vartheta^{2}\right) \cosh (\sqrt{z} D \cos \psi)\right. \\
& +\left(z-\vartheta^{2}\right) \cos (\sqrt{z} D \sin \psi) \\
& +2 \frac{\cos \varphi}{|\cos \varphi|} \vartheta \sqrt{z}(\sin \psi \sinh (\sqrt{z} D \cos \psi) \\
& -\cos \psi \sin (\sqrt{z} D \sin \psi))]
\end{array}
$$

где

$$
\begin{gathered}
2 \psi=\arccos \left(-\frac{\vartheta^{2}+4\left(\kappa_{1}^{2}-\kappa_{2}^{2}\right)}{z}\right), \\
z=\sqrt{\left[\vartheta^{2}+4\left(\kappa_{1}^{2}-\kappa_{2}^{2}\right)\right]^{2}+\left(8 \kappa_{1} \kappa_{2} \cos \varphi\right)^{2}}, \\
\vartheta=4 \pi n_{0} \sin \theta_{\mathrm{B}}\left(\sin \theta-\sin \theta_{\mathrm{B}}\right) / \lambda, \\
A(\theta)=\exp \left(-2 \alpha_{0} D\right), \quad D=d / \cos \theta, \\
\kappa_{1}=\pi n_{1} / \lambda, \quad \kappa_{2}=\alpha_{1} / 2,
\end{gathered}
$$

$\theta_{\mathrm{B}}$ - угол Брэгга в среде, $\alpha_{0}$ и $n_{0}-$ соответственно средние коэффициент поглощения и показатель преломления материала, $n_{1}$ и $\alpha_{1}-$ амплитуды их модуляции, $d-$ эффективная толщина голограммы, $\lambda-$ длина волны считывающего излучения; $\kappa_{1}$ и $\kappa_{2}-$ действительная и мнимая части константы взаимодействия $\left(\kappa=\kappa_{1}-i \kappa_{2}\right)$.

Форма контура угловой селективности нулевого порядка голограмм зависит от их природы (рис. 1). 

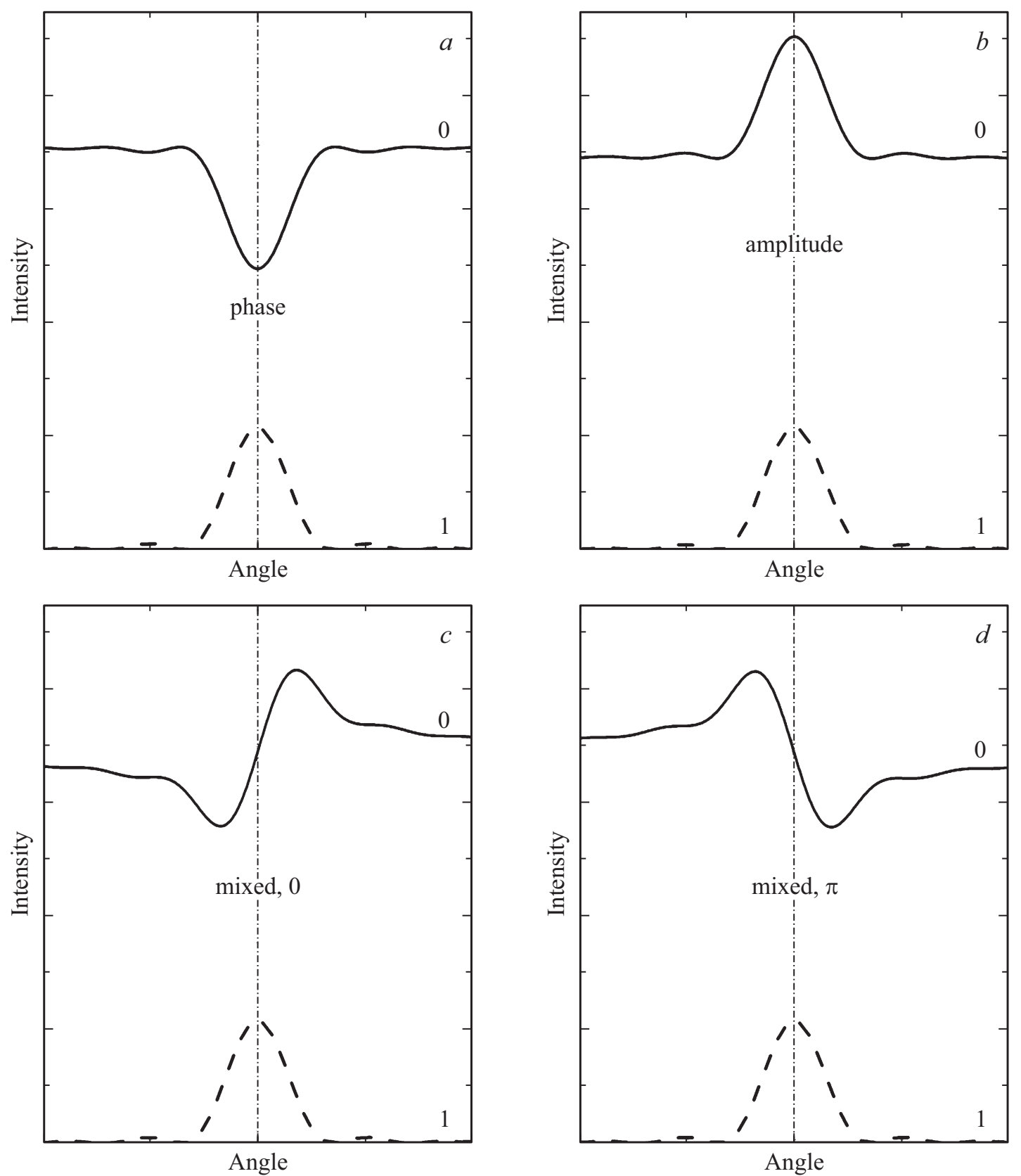

Рис. 1. Рассчитанные по формулам (1) и (2) примеры контуров угловой селективности нулевого и первого порядков дифракции объемных пропускающих голограмм: фазовой $(a)$, амплитудной $(b)$ и смешанных $(c, d)$ с синфазной $(c)$ и противофазной модуляцией показателя преломления и коэффициента поглощения $(d)$.

В случае чисто фазовых решеток максимуму дифракции 1-го порядка соответствует минимум дифракции 0-го (рис. $1, a$ ), для амплитудных (рис. $1, b$ ) наблюдается эффект Бормана [7] - увеличение пропускания (дифракции нулевого порядка) при угле падения считывающего излучения, соответствующему максимуму 1-го порядка дифракции (угле Брэгга). В случае амплитуднофазовых голограмм максимум пропускания смещен относительно угла Брэгга [3] в сторону больших углов, если модуляции показателя преломления и поглощения решетки синфазны (рис. 1,c), либо в сторону меньших углов в случае, если решетки находятся в противофазе (рис. $1, d$ ).

Характерные формы контуров селективности позволяют судить об амплитудно-фазовой природе голограмм по самому их виду; аппроксимируя измеренные в эксперименте контуры угловой селективности при помощи уравнений (1) и (2), можно рассчитать значения амплитуды модуляции показателя преломления и коэффициента поглощения, а также других параметров. Такой подход показал свою эффективность в исследовании голограмм, записанных в аддитивно окрашенных 
кристаллах фторида кальция, контуры селективности которых могут принимать все 4 характерные формы, показанные на рис. 1, в зависимости от длины волны, на которой производится измерение, и типа центров окраски, составляющих голограмму [8-10].

В настоящей работе контуры селективности в их связи с модуляцией оптических параметров применены к объемным голограммным решеткам, записанным в полимерном материале с фенантренхиноном $(\Phi X)$. Механизм формирования голограмм в таком материале основан на фотохимическом взаимодействии молекул $Ф \mathrm{X} \mathrm{с} \mathrm{их}$ полимерным окружением и диффузии непрореагировавших молекул, благодаря которой происходит усиление (или проявление) голограмм. Материалы такого рода разрабатываются и исследуются с конца 1980-х гг. [11]. Принцип их действия, история создания, различные модификации, применение в селективных оптических элементах, из которых наиболее известны узкополосные спектральные селекторы для лазерной локации космических объектов, рассмотрены в обзоре [12]. Исходный материал с ФХ был жестким полимерным стеклом без мономера в отличие от некоторых более поздних вариантов, содержащих значительное количество мономера, взаимодействие ФХ с которым сильно меняет свойства материала, приближая его к классическим фотополимерам. Детальная модель процессов, происходящих в полимерных регистрирующих средах с ФХ, представлена в $[13,14]$ и других работах.

Непосредственно после экспозиции разница показателей преломления фотопродукта и ФХ-ПММА обеспечивает фазовую модуляцию, в то время как неравномерное распределение оставшегося ФХ создает амплитудную решетку [15] из-за разницы коэффициента поглощения ФХ (сам полимер в видимой области спектра прозрачен) и фотопродукта. Однако с течением времени вследствие диффузии непрореагировавшего ФХ должно происходить разрушение амплитудной составляющей. Наиболее очевидный способ удостовериться в справедливости данного предположения - получить численное значение вкладов амплитудной и фазовой модуляции в дифракционную эффективность голограмм.

\section{Эксперимент}

\section{Светочувствительный материал}

Для записи голограммных решеток использованы образцы материала из полиметилметакрилата (ПММА) с ФХ толщиной 6-7 mm, изготовленные путем радикальной полимеризации в массе смеси мономера метилметакрилата, $\Phi \mathrm{X}(0.6 \%)$ и инициатора полимеризации азо-бис-изобутиронитрила, до максимальной достижимой степени полимеризации. Другие варианты материалов могут содержать значительно более высокую концентрацию ФХ или иметь композицию, способствующую значительным фотоиндуцированным изменениям оптических характеристик материала (например, в

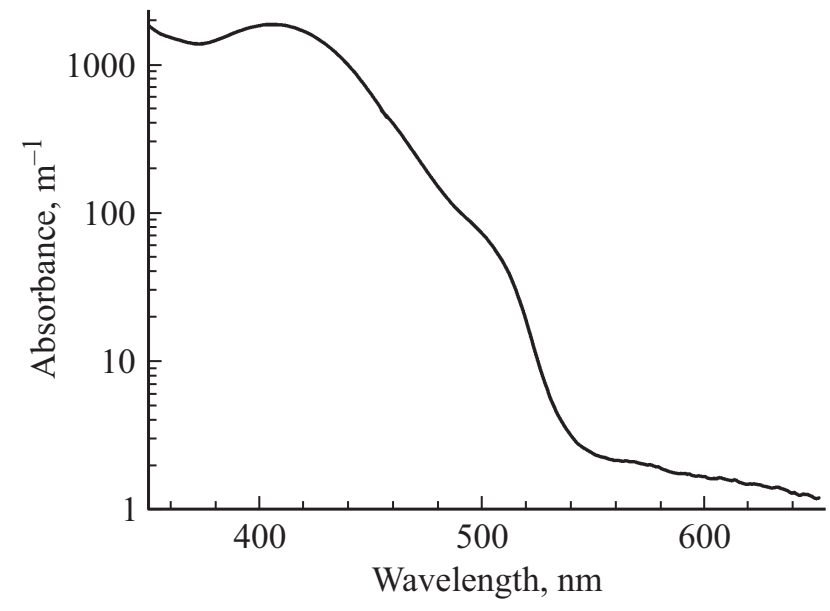

Рис. 2. Спектр поглощения ФХ в ПММА.

результате полимеризации); ни избранная композиция, ни режим записи или обработки голограммы не были направлены на достижение рекордных параметров.

Для построения спектра поглощения ПММА с ФХ использованы слои одинаковой композиции, но различной толщины, полученные как методом полимеризации в массе $(1-6 \mathrm{~mm})$, так и путем высушивания раствора смеси ПММА и ФХ в дихлорэтане (пленки [16] толщиной 10-100 $\mu \mathrm{m})$. Измерение спектров производилось на спектрофотометре Evolution 300 (Thermo Scientific) для каждого из образцов в той области спектра, где его оптическая плотность находится в диапазоне $0.1-2.5$, после чего спектры были соединены в один, включающий спектральную область длинноволновой полосы поглощения ФХ (максимум около $405 \mathrm{~nm})$, где коэффициент поглощения меняется более чем на три порядка (рис. 2).

Для создания объемных голограмм значительной толщины (> $5 \mathrm{~mm})$, пригодных к исследованию их оптических параметров, целесообразно использовать регистрирующее излучение, слабо поглощаемое образцом (применительно к полимерным материалам с ФХ спектр регистрирующего излучения должен находиться на длинноволновой границе спектра поглощения $\Phi \mathrm{X}$ ); в противном случае неравномерная освещенность образца по толщине и приведет к неоднородности записи голограммы, которая не учитывается в используемом в настоящей работе математическом аппарате.

Под воздействием видимого излучения происходит фотовосстановление $\Phi Х$, сопровождающееся обесцвечиванием - снижением поглощения видимого излучения. При этом возрастает поглощение продуктов фотореакции в ближней УФ области, как можно видеть на рис. 3. Такие спектральные изменения вносят вклад в формирование голограмм (сформированные за их счет решетки рассматриваются как своего рода скрытое изображение), но основной интерес полимерные материалы с ФХ представляют благодаря следующему за записью скрытого изображения проявлению (или усиле- 

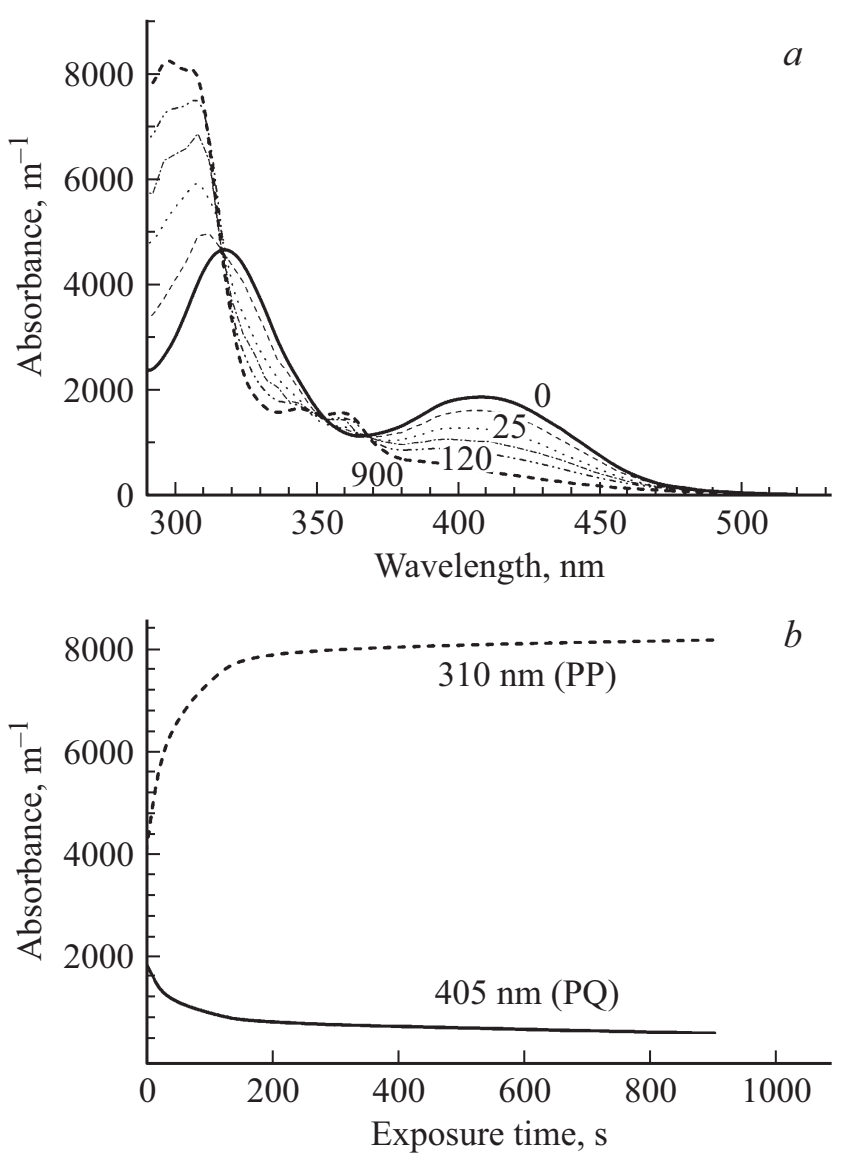

Рис. 3. Динамика фотообесцвечивания ФХ в ПММА: (a) спектры поглощения ПММА с ФХ, измеренные до (0) и после облучения светом ртутной лампы с длиной волны $436 \mathrm{~nm}$ в течение 25, 120 и $900 \mathrm{~s}$; $(b)$ изменение поглощения на длинах волн 405 и $310 \mathrm{~nm}$ - в максимумах полос поглощения соответственно ФХ (PQ) и продукта его фотохимического преобразования (РP) - в ходе экспонирования.

нию), обусловленному диффузией непрореагировавших молекул $\Phi \mathrm{X}$, а происходящая при записи фотохимическая реакция ценна не столько обесцвечиванием, сколько связыванием ее продукта с полимерными цепями. Интересно, что сдвиг поглощения в коротковолновую область сопровождается не снижением, а увеличением показателя преломления [11], что было недавно подтверждено с использованием метода цифровой интерферометрии [17].

\section{Запись голограммных решеток}

Пропускающие голограммные решетки с пространственным периодом $3.1 \mu \mathrm{m}$ были записаны в объеме полимерного образца при помощи коллимированного пучка непрерывного излучения твердотельного Nd:YAG-лазера с диодной накачкой и удвоением частоты $(532 \mathrm{~nm}$, $200 \mathrm{~mW}$, Wicked Lasers) в симметричной схеме (рис. 4). Для контроля динамики записи в ходе экспонирования периодически кратковременно перекрывался один из

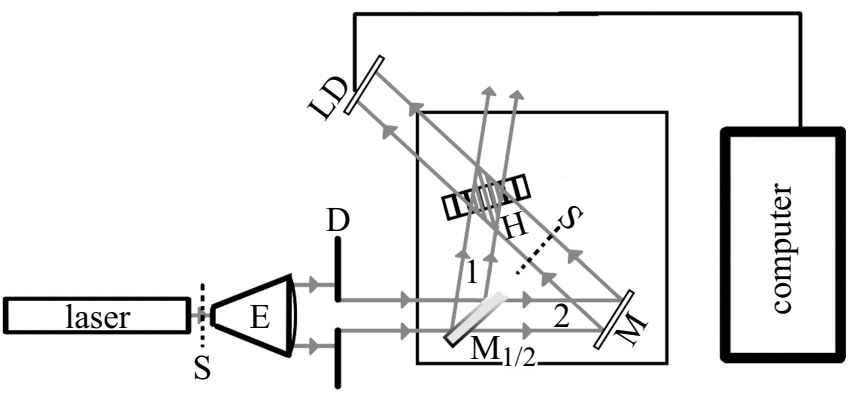

Рис. 4. Схема записи голограмм: лазер, расширитель пучка $\mathrm{E}$, диафрагма $\mathrm{D}$, делитель $\mathrm{M}_{1 / 2}$ зеркало $\mathrm{M}$, затвор $\mathrm{S}$, светочувствительный материал с голограммой $\mathrm{H}$, фотоприемник $\mathrm{LD}$, компьютер со схемой регистрации.

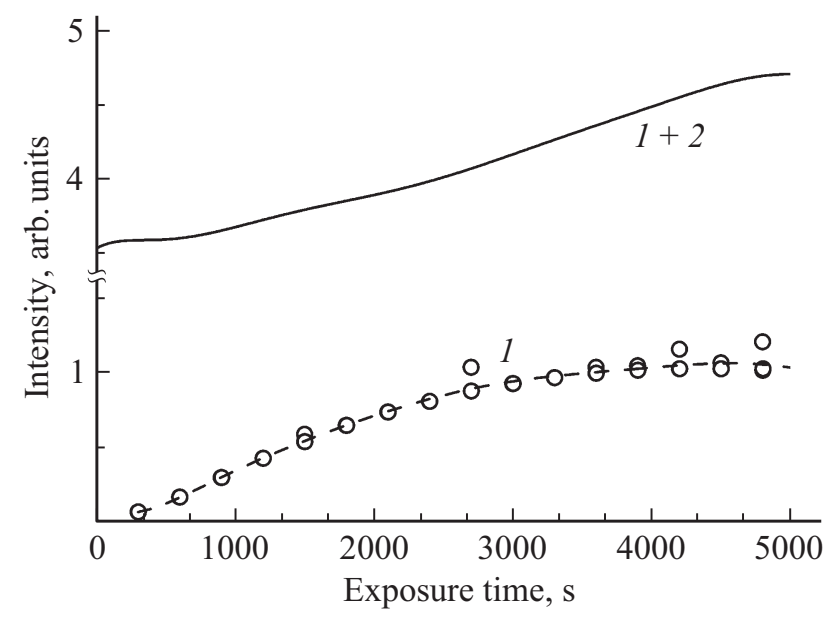

Рис. 5. Изменение в ходе записи интенсивности света, распространяющегося за материалом с голограммой в направлении записывающего пучка 2 (рис. 4) при падении на материал только дифрагирующей части пучка 1 при перекрытом пучке 2 $(1$, точки) и смеси записывающих пучков 1 и $2(1+2$, сплошная линия; разрывы на ней в моменты перекрывания пучка не показаны).

двух записывающих пучков и измерялась интенсивность света, дифрагирующего в его направлении (рис. 5). Запись прекращалась, когда рост интенсивности дифрагирующего пучка существенно замедлялся.

Дифракционная эффективность зарегистрированных голограмм, измеренная после экспонирования в течение $90 \mathrm{~min}$ на длине волны $532 \mathrm{~nm}$, составила от 18 до 23\%.

\section{Измерение контуров угловой селективности}

Измерение контуров угловой селективности проводилось при помощи лазеров с излучением длин волн 450, $473 \mathrm{~nm}$ - в области сильного поглощения ФХ, $532 \mathrm{~nm}$ - на краю полосы поглощения и $633 \mathrm{~nm}-$ вне ее, непосредственно после записи голограмм и затем после выдерживания их в течение 7 дней при температуре $50-60^{\circ} \mathrm{C}$. 
Параметры голограммы до и после диффузионного проявления, полученные путем аппроксимации измеренных контуров угловой селективности

\begin{tabular}{c|c|c|c|c|c|c}
\hline \multirow{2}{*}{$\begin{array}{c}\text { Длина } \\
\text { волны, nm }\end{array}$} & \multicolumn{2}{|c|}{$\begin{array}{c}\text { Амплитуда модуляции } \\
\text { показателя преломления }\end{array}$} & \multicolumn{2}{c|}{$\begin{array}{c}\text { Амплитуда модуляции } \\
\text { коэффициента поглощения, } \mathrm{m}^{-1}\end{array}$} & \multicolumn{2}{c}{ Эффективная толщина, тт } \\
\cline { 2 - 7 } & до проявления & после проявления & до проявления & после проявления & до проявления & после проявления \\
\hline 450 & $(5.5 \pm 0.5) \cdot 10^{-6}$ & $(8 \pm 1) \cdot 10^{-5}$ & $120 \pm 2$ & $<1$ & $6.0 \pm 0.5$ & $7.4 \pm 0.4$ \\
473 & $(1.1 \pm 0.1) \cdot 10^{-5}$ & $(8.2 \pm 0.7) \cdot 10^{-5}$ & $40 \pm 1$ & $<1$ & $6.6 \pm 0.4$ & $7.4 \pm 0.3$ \\
532 & $(1.6 \pm 0.2) \cdot 10^{-5}$ & $(1.0 \pm 0.2) \cdot 10^{-4}$ & $0 \pm 1$ & $<1$ & $6.6 \pm 0.4$ & $7.3 \pm 0.4$ \\
633 & $(1.6 \pm 0.2) \cdot 10^{-5}$ & $(6 \pm 1) \cdot 10^{-5}$ & $0 \pm 1$ & $<1$ & $6.6 \pm 0.4$ & $7.0 \pm 0.2$
\end{tabular}

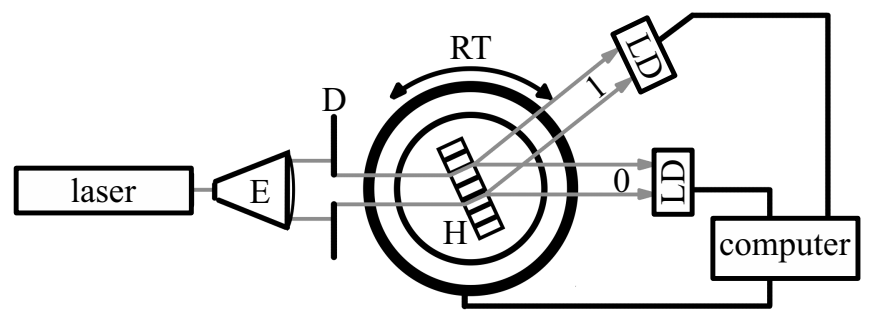

Рис. 6. Схема измерения угловой зависимости дифракционной эффективности (контура угловой селективности): лазер, расширитель пучка $\mathrm{E}$, диафрагма $\mathrm{D}$, поворотный столик $\mathrm{RT}$, голограмма $\mathrm{H}$ на нем, фотоприемники $\mathrm{LD}$, регистрирующие 1-й и 0-й порядки дифракции, компьютер со схемой управления и ввода сигнала.

Контуры угловой селективности измерялись путем поворота установленной на моторизованном столике голограммы по отношению к коллимированному пучку считывающего излучения в диапазоне углов от -2 до $+2^{\circ}$ от угла Брэгга с шагом $0.001^{\circ}$. Интенсивность прошедшего через голограмму (дифрагировавшего в 0-й порядок) и дифрагировавшего на ней в 1-й порядок пучков одновременно регистрировалась фотодиодами и записывалась вместе с соответствующим значением угла поворота столика. Схема использованного для измерения стенда приведена на рис. 6. Угол Брэгга определялся по результатам измерения зависимости интенсивности проходящего света от угла в диапазоне $15^{\circ}$ от нормали к поверхности.

\section{Результаты и их обсуждение}

Примеры контуров угловой селективности, измеренных непосредственно после записи голограмм на длинах волн 450 и $633 \mathrm{~nm}$, показаны на рис. 7. Формы контуров позволяют отнести их к амплитудно-фазовой решетке с преобладающей амплитудной составляющей, сдвинутой на половину периода относительно фазовой $(450 \mathrm{~nm})$, и к чисто фазовой решетке $(633 \mathrm{~nm})$. Такое наблюдение вполне соответствует тому, что на длине волны $450 \mathrm{~nm}$ велико поглощение ФХ и изменение поглощения в ходе фототрансформации, а на $633 \mathrm{~nm}$ поглощение ФХ и продуктов его фототрансформации почти полностью отсутствует (рис. 2 и 3,a). Контуры селективности, измеренные после длительного выдерживания образцов при повышенной температуре, указывают на чисто фазовый характер проявленных голограмм на любой длине волны.

Для количественного описания решеток измеренные зависимости дифракционной эффективности 1-го и нулевого порядков дифракции совместно (с общим набором параметров) аппроксимировались с использованием выражений (1) и (2). В результате были получены значения амплитуды модуляции показателя преломления, коэффициента поглощения и эффективной толщины голограммы, приведенные в таблице и на рис. 8. Эффективная толщина голограммы близка к физической толщине материала, что свидетельствует в пользу однородности записи по толщине. Значения амплитуды модуляции показателя преломления находятся в пределах от $5 \cdot 10^{-6}$ до $10^{-4}$, а коэффициента поглощения — до $140 \mathrm{~m}^{-1}$ значительно ниже результатов, приведенных, например, в работе [15], что, возможно, отчасти объясняется более низкой концентрацией $Ф \mathrm{X}$ в образцах, исследованных в настоящей работе.

Преимущественно амплитудная природа непроявленной голограммы при измерении на $450 \mathrm{~nm}$ иллюстрируется на рис. 7, $a$ рассчитанными контурами селективности чисто фазовой и чисто амплитудной голограмм со значениями модуляции показателя преломления и коэффициента поглощения, равными полученным в результате аппроксимации значениям этих параметров смешанной голограммы. Дифракционная эффективность 1-го порядка амплитудной составляющей выше, чем фазовой, а высота максимума ее эффективности нулевого порядка превосходит глубину провала в контуре селективности фазовой составляющей.

На остальных длинах волн решетка имеет преимущественно или полностью фазовый характер сразу после записи. Амплитудная (обусловленная модуляцией поглощения) модуляция непроявленной решетки снижается при увеличении длины волны в соответствии со спектром поглощения (рис. 2). В результате диффузионного проявления модуляция поглощения, связанного в основном с молекулами $Ф Х$, исчезает, хотя сами молекулы продолжают существовать и поглощать свет. 

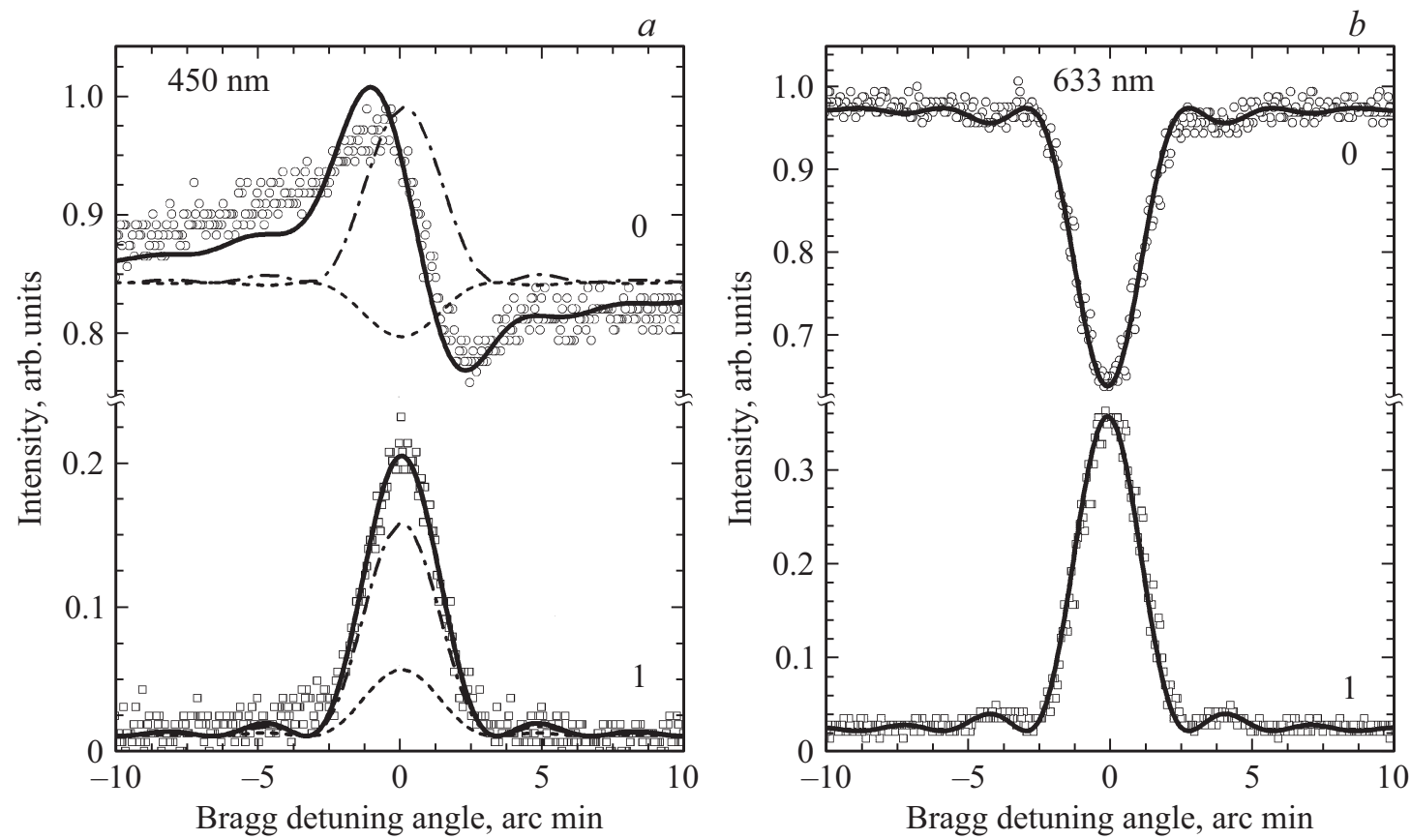

Рис. 7. Контуры угловой селективности: дифракционная эффективность 0-го (круги) и 1-го (квадраты) порядков, измеренные при считывании голограммы излучением $450 \mathrm{~nm}(a)$ и $633 \mathrm{~nm}(b)$ до усиления; результат их аппроксимации при помощи уравнений (1) и (2) (сплошные линии); рассчитанные по тем же формулам контуры селективности соответственно фазовой и амплитудной составляющих решетки (соответственно штриховые и штрихпунктирные линии).
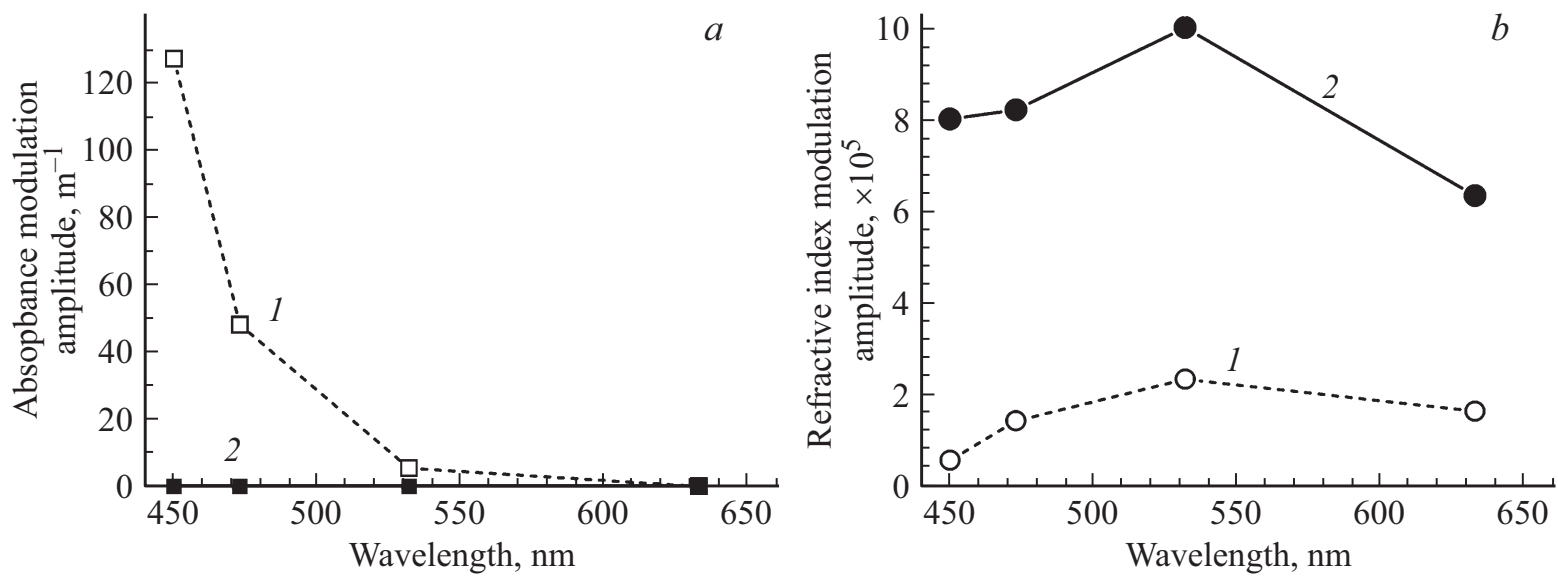

Рис. 8. Значения амплитуды модуляции коэффициента поглощения $(a)$ и показателя преломления $(b)$, рассчитанные по результатам аппроксимации контуров угловой селективности, измеренных на длинах волн 450, 473, $532 \mathrm{n} 633 \mathrm{~nm}$ до (1) и после (2) диффузионного проявления голограммной решетки.

Противофазность амплитудной и фазовой модуляции смешанных решеток, на которую указывает максимум дифракционной эффективности нулевого порядка при угле, меньшем угла Брэгга (рис. 7,a), может рассматриваться как иллюстрация концепции противофазных, или дополнительных решеток $[11,18]$, лежащей в основе механизма формирования голограмм в полимерных материалах с ФХ. Однако отнесение амплитудной модуляции исключительно к ФХ, а фазовой - исключительно к связанному с полимерными цепями продукту его фототрансформации было бы чрезмерным упрощением, на что указывает, в частности, заметное увеличение фазовой модуляции после диффузионного проявления (рис. 8, $b$ ).

\section{Заключение}

В ходе работы методика определения параметров модуляции голограмм, основанная на анализе контуров угловой селективности, была применена к полимерному материалу с $\Phi \mathrm{X}$, реализующему принцип формирования 
голограмм за счет фотоприсоединения и диффузии. Рассмотрение контуров угловой селективности позволяет получить информацию об амплитудно-фазовой природе голограмм без использования математического аппарата, по взаимному расположению экстремумов 0-го и 1-го порядков дифракции.

Подтверждено представление о противофазной модуляции показателя преломления и коэффициента поглощения в исследуемом материале. Показано, что до усиления голограмм они являются амплитудно-фазовыми для света с длиной волны в области поглощения $\Phi \mathrm{X}$, а после проявления - фазовыми. Вне полосы поглощения голограммы являются фазовыми как до, так и после проявления. Полученные в результате измерения и аппроксимации значения амплитуды модуляции показателя преломления находятся в пределах от $5 \cdot 10^{-6}$ до $10^{-4}$, а амплитуды модуляции коэффициента поглощения доходят до $140 \mathrm{~m}^{-1}$.

Авторы признательны Ю.Л. Корзинину и А.П. Попову за плодотворное обсуждение работы и предоставленную возможность воспользоваться измерительным стендом НПК СПП, а О.В. Бандюк и А.Н. Катрузову - за предоставленные для опытов синтезированные ими образцы светочувствительного материала.

Работа была выполнена при финансовой поддержке Правительства Российской Федерации (грант 074-U01).

\section{Список литературы}

[1] Kogelnik H. // Bell Syst. Tech. J. (USA). 1969. V. 48. P. 2909.

[2] Алексеев-Попов А.В., Дьяченко Н.Г., Мандель В.Е., Тюрин А.В. // Опт. и спектр. 1979. Т. 47. С. 583.

[3] Carretero L., Madrigal R.F., Fimia A., Blaya S., Belen$\operatorname{dez} A$. // Opt. Lett. 2001. V. 26. P. 786.

[4] Neipp C., Pascual I., Belendez A. // Optics Express. 2002. V. 10. P. 1374.

[5] Fally M., Ellabban M., Drevenšek-Olenik I. // Optics Express. 2008. V. 16. P. 6528

[6] Fally M., Ellabban M., Drevenšek-Olenik I. // Optics Express. 2009. V. 17. P. 23350.

[7] Russell P.S.J., Solymar L. // Appl. Phys. A. 1980. V. 22. P. 335.

[8] Щеулин А.С., Вениаминов А.В., Корзинин Ю.Л., Ангервакс А.Е., Рыскин А.И. // Опт. и спектр. 2007. Т. 103. № 4. C. 668-672; Shcheulin A.S., Veniaminov A.V., Korzinin Yu.L., Angervaks A.E., Ryskin A.I. // Opt. Spectrosc. 2007. V. 103. N 4. P. 655. doi 10.1134/S0030400X07100207

[9] Щеулин А.С., Ангервакс А.Е., Вениаминов А.В., Захаров В.В., Рыскин А.И. // Опт. и спектр. 2012. V. 113. № 6. P. 712; Shcheulin A.S., Angervaks A.E., Veniaminov A.V., Zakharov V.V., Ryskin A.I. // Opt. and Spectrosc. 2012. V. 113. N 6. P. 638. doi 10.1134/S0030400X12120077

[10] Shcheulin A.S., Angervaks A.E., Zakharov V.V., Veniaminov A.V., Ryskin A.I. // JOSA B. 2014. V. 31. N 2. P. 248. doi 10.1364/JOSAB.31.000248

[11] Вениаминов А.В., Гончаров В.Ф., Попов А.П. // Опт. и спектр. 1991. Т. 70. В. 5. С. 864; Veniaminov A.V., Goncharov V.F., Popov A.P. // Opt. Spectrosc. 1991. V. 70. N 5. P. 505.
[12] Вениаминов А.В., Могильный В.В. // Опт. и спектр. 2013. T. 115. C. 1014; Veniaminov A.V., Mahilny U.V. // Opt. Spectrosc. 2013. V. 115. N 6. P. 906. doi 10.1134/S0030400X13120199

[13] Qi Y., Li H., Tolstik E., Guo J., Gleeson M.R., Matusevich V., Kowarschik R., Sheridan J.T. // JOSA B. 2013. V. 30. P. 3298. doi 10.1364/JOSAB.30.003298

[14] Qi Y., Li H., Tolstik E., Guo J., Gleeson M., Sheridan J.T. // Opt. Commun. 2015. V. 338. P. 406. doi 10.1016/j.optcom.2014.10.010

[15] Matusevich V., Matusevich A., Kowarschik R., Matusevich Y.I., Krul L.P. // Optics Express. 2008. V. 16. P. 1552.

[16] Вениаминов А.В., Бандюк О.В., Андреева О.В. // Оптический журнал. 2008. Т. 75. № 5. C. 28; Veniaminov A.V., Bandyuk O.V., Andreeva O.V. // J. Opt. Technol. 2008. V. 75. N 5. P. 306-310. doi 10.1364/JOT.75.000306

[17] Manukhin B.G., Chivilikhin S.A., Schelkanova I.J., Andreeva N.V., Materikina D.A., Andreeva O.V. // Appl. Opt. 2017. V. 56. P. 7351. doi 10.1364/AO.56.007351

[18] Park S., Sung J., Kim H., Chang T. // J. Phys. Chem. 1991. V. 95. P. 7121. 